geon, who has any private practice to atlend to, undertakes to be at his hospital in the middle of the day, at one or two o'clock. Moreover, as the visit would, in such a case, be made before the business of the day can be said to have commenced, the medical officers would not, as is now often the case, grudge the time they devote to their patients, and rapidly perambulate the wards, giving a cursory glance at the patients under their care, and trusting to the apothecary or housesurgeon for more careful examination.

The three points to which I have called your attention,-the nomination of the medi. cal functionaries by concours, their daily attendance, and their attendance early in the moruing, constitute the principal difference between French and English hospitals, and account for the superior usefulness, which in my opinion is incontestible, of the former. If the subscribers to the intended hospital, both medical and non-medical, will bear in mind and adopt these suggestions, $I$ am convinced that they will render the charity infinitely more efficacious as regards those whose sufferings it is destined to relieve, and, at the same time, confer a lasting benefit on the medical profession, on the one hand, and on the public on the other. I have the honour to be, Sir, your obedient servant,

Henry Bennet, M.D.,

Four years resident House-Physician (by concours) to the Hospitals of Saint Louis, La Salpetrière, and La Pitié, Paris.

Cambridge-square, Hyde-park, Feb. 17, 1844.

\section{MEDICAL REMUNERATION IN EMIGRANT VESSELS.}

\section{To the Editor of The Lancet.}

SIR,-For the benefit of many of the junior members of the profession who, on having completed their course of education in London, are frequently induced to adopt any honourable source of employment, and among which that of the surgeoncy of a merchant or emigrant vessel is frequently the one selected (many of which advertise to carry their "skilful and experienced surgeons"), the following extracts from an article which appeared in the "Colonial Magazine" of December last, cannot be too widely disseminated for a just appreciation of the merits of the latter duty, ere entered upon by those more inexperienced.

"As the discipline of an emigrant vessel cannot be coercive, the requisite regulations to ensure health and comfort are more diffi. cult to enfurce than even in a convict ship. And few, if any, indeed, properly qualifed, would enter upon the service twice under the present wretched scale of remuneration, who had experienced the delay in the colonies before even that was fully dis- charged, from their frequently having charge of ineligible parties. The attendant port expenses, and there being no provision for a return passage, reduces also the remuneration of the bounty system of $10 \mathrm{~s} 6 \mathrm{~d}$, now $10 \mathrm{~s}$, per head, to nothing more (notwithstanding the hazard) than an 'assistant's emolument,' shown as follows :-

200 emigrants (and that, if anything, exceeds the average number, although some few vessels have taken $\mathbf{3 0 0}$ and upwards) at $10 \mathrm{~s} 6 \mathrm{~d} . .$.

Expenses in harbour for six weeks (and where there are ineligible emigrants full that time will be expended in in. vestigating whether the surgeon was ignorant of their being so on embarking), in correspondence, \&c.; and an average of $2 l$. per week all who have visited the colony can attest will not be more, in the towns, than sufficient to supply actual necessaries............ $£ 12$

Additional outfit for the voyages, out and home, to the apparel that may be considered requisite if otherwise employed, at but the small sum of $\ldots \ldots \ldots \ldots \ldots$. And the homeward passage money, to do duty as surgeon, at the average (which, if anything, is under the mark) of 40l.; and saying such is obtainable in the period of six weeks, what is the balance of the bounty, after the hazard and anxiety attending such an undertaking...........

Balance ............

\pm 33 !

Thus, a twelvemonth's hazardous employment, and it is known by experience that the outward and homeward passage to the colonies generally exceeds eleven, leaves but a paltry $33 l$, - all the surgeon can with any certainty calculate upon.

It is generally suggested by the shipagents and others that after the disembarkation of the emigrants in Australia, vessels may be found, proceeding via India to England, in which the services of a medical man will be adequately remunerated ; but let not such fables be believed; the shipping interest of the colonies, especially at the present time, will not allow of it, and the chances that he may not, and will not, are at least forty-nine to fifty against it.

The conviction of the truth of these remarks has prompted your correspondent to offer them for circulation through the medium of your valuable Journal, in order that $3 \mathrm{C} 2$ 
the unwary and inexperienced may not be imposed upon, and that the duty devolving upon the surgeon superintendent of an emi. grant vessel may meet with a better requital, and thus become more worthy of the attention of those who are alone qualified for such a duty, and of whom the remuneration of the present system is unworthy of notice. I remain, $\mathrm{Sir}$, your obedient servant,

London, Feb. 5, 1844.

T. Churchilt, Surgeon.

\section{TIE IANCET.}

\section{London, Saturday, February 24, 1844.}

An open Meeting of the Conmittee of the Medical Profession was held at the Crown-and-Anchor Tavern, Strand, on Wednesday evening last. There were upwards of a hundred gentlemen present, of first-rate respectability, many of them far advanced in years, and whose venerable appear. ance added to the interesting character and dignity of the scene. An address to the profession, written by Dr. Ly and received the hearty approval of the com. mittee. It was referred to a sub-committee, and from that body it is to be transferred, for further consideration and approval, to an aggregate meeting of the profession, which is to be held in London, in the month of $\mathrm{MARCH}_{\mathrm{A}}$ next. The committee is fully empowered to make the necessary arrangements for the accomplishment of that important object. The committee propose, at the meeting in question, to present a brief report of their labours, and to recommend the united action of the whole profession in a general assembly, and then to resign their powers to that assembly, considering that the labour of medical reform, in order to be successfully pursued, must be undertaken by the entire profession, and not by a single committee of its members, for whose limited numbers the task would be by far too Herculean to be conducted with even the hope of a successful issue. The commiltee has determined most wisely; and we are confident that the general voice of the profession will be loudly and ardently expressed in facour of the discreet course which the members of that body have determined to pursue. A report of the proceedings, developing the proposed plan for future operations, will be published in the ensuing number of our Journal. We regret that a misconception on the part of our reporter has prevented the insertion of an account of the proceedings in THE LANCET of the present week.

Among the numerous charities which modern philanthropy is endeavouring to esta. blish in our great metropolis, there is none which is more deserving of effectual support, and none which, we are happy to say, is more likely to obtain it, than the intended Marylebone and Paddington Hospital. The want of hospital accommodation for the relief of the industrious poor who shrink from the humiliation entailed upon them by a residence in a workhouse infirmary, is felt severely, even in those parishes which are the most munificently endowed in that respect; what must it then be in the district of London to the north-west of Portlandplace, where, with a population of 150,000 inhabitants, occupying an area of four square miles, the only institution afford. ing indoor relief, with the exception of the Marylebone Workhouse Infirmary, is the Western Dispensary, which has but six beds to dispose of.

At a general meeting of the subscribers to the proposed charity, which took place on the 14th instant, and of which we last week gave an account, a report was read, from which it appears that the prospects of the Paddington Hospital are now so good that its early erection may be looked upon as a matter of certainty. The funds already subscribed amount to above eight thousand pounds, comprising a munificent sum of two thousand which has been lately presented by an anonymous benefactor. This donation has been made subject to the condition that the building of the hospital will be commenced within a twelvemonth. At present the committee is bound by a motion, paissed 